\title{
Commentary: Will it go platinum? Microcoil localization as an adjunct to thoracoscopic wedge resection
}

\author{
Benjamin Wei, MD, and Peter Abraham, MD
}

\author{
From the Division of Cardiothoracic Surgery, Department of Surgery, University of Alabama-Birmingham Med- \\ ical Center, Birmingham, Ala. \\ Disclosures: Authors have nothing to disclose with regard to commercial support. \\ Received for publication April 23, 2019; accepted for publication April 23, 2019. \\ Address for reprints: Benjamin Wei, MD, Division of Cardiothoracic Surgery, Department of Surgery, University \\ of Alabama-Birmingham Medical Center, Zeigler Research Building, 703 19th Street South, Birmingham, AL \\ 35294 (E-mail: bwei@uab.edu). \\ J Thorac Cardiovasc Surg 2019;158:603 \\ 0022-5223/\$0.00 \\ Published by Elsevier Inc. on behalf of The American Association for Thoracic Surgery \\ https://doi.org/10.1016/j.jtcvs.2019.04.075
}

The challenge of resecting small or nonsolid nodules in the age of minimally invasive thoracic surgery, has been answered by the development of various preoperative localization techniques for intraoperative guidance. For more than 20 years, these techniques, such as the injection of different dyes and the placement of various wires, have been utilized by thoracic surgeons to guide intraoperative decision making regarding nodule resection. Computed tomography (CT)-guided platinum microcoil placement is among the localization techniques that have emerged. McGuire and colleagues ${ }^{1}$ provide a 5-year update on their use of CT-guided platinum microcoils as an adjunct localization technique for the resection of small or nonsolid lung nodules. They ultimately conclude that CT-guided platinum microcoil lung surgery is safe and suitable even for poorrisk patients.

One hundred percent of nodules were successfully localized and resected with the assistance of CT-guided microcoil placement. The adverse event rate associated with placement of the microcoils is rather high at 60.8\% (59 out of 97), but all recorded events were minor, such as postprocedure pneumothorax or lung hematoma. No major adverse events were noted with microcoil placement. Mean fluoroscopy time per case was 50 seconds, and mean radiation exposure was only $6.3 \mathrm{mGy}$. The investigators do not provide details about the trend in radiation exposure or fluoroscopy time as their experience with the technique increased. No data are provided regarding either case duration or duration of time between coil localization and resection. This would be interesting information for surgeons interested in adopting the technique. On the other hand, the investigators have provided an extremely detailed, nearly step-by-step guide along with helpful video demonstrating both the localization and resection stages of their technique.

As the largest reported single-center study for microcoilguided pulmonary resection, McGuire and colleagues ${ }^{1}$

\section{References} Surg. 2015;149:26-31

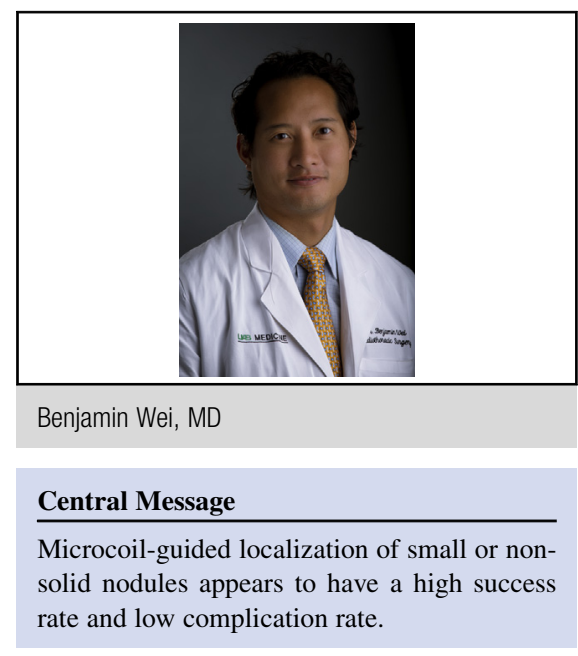

See Article page 594.

bolster an already compelling case for the widespread use of platinum microcoil technology. Successful adoption of microcoil guidance could significantly limit the need for thoracotomy and palpation of small or nonsolid lung nodules. $^{2}$ Other localization techniques have welldocumented disadvantages, such as difficulty with precision of localization (eg, dyes and contrast injection) and dislodgement (eg, hookwires and spiral wires). Compared with ultrasound or dye techniques, microcoil-guided resection has the disadvantage of requiring 2 steps in different theaters (radiology suite and operating room). The use of a hybrid operating room may eliminate this concern. ${ }^{3}$ Time will tell which localization technique becomes the dominant method. It is possible to imagine a future in which the location of a nodule could be superimposed on thoracoscopic video images of the lung in real time, so that all of these localization techniques become obsolete.

1. McGuire AL, Vieira A, Grant K, Mayo J, Sedlic T, Choi J, et al. Computed tomography-guided platinum microcoil lung surgery: a cross-sectional study. $J$ Thorac Cardiovasc Surg. 2019;158:594-600.

2. Finley RJ, Mayo JR, Grant, Clifton JC, English J, Leo J, et al. Preoperative computed tomography-guided microcoil localization of small peripheral pulmonary nodules: a prospective randomized controlled trial. $J$ Thorac Cardiovasc

3. Chen PH, Hsu HH, Yang SM, Tsai TM, Tsou KC, Liao HC, et al. Preoperative dye localization for thoracoscopic lung surgery: hybrid versus computed tomography room. Ann Thorac Surg. 2018;106:1661-7. 